Safety infusion devices

\title{
Who is responsible for the safety of infusion devices? It's high time for action!
}

\section{K Taxis}

M edication errors are unacceptably common. They occur during each step in the process of providing medication to hospital inpatients; prescribing, preparation, and administration. A recent UK study found a prescribing error in $1.5 \%$ of all medication orders written (a potentially serious prescribing error in $0.4 \%) .{ }^{1}$ Even higher error rates are associated with the administration of medication, in particular with intravenous medication. One or more errors occurred in about half of all intravenous drug preparations and administrations and $1 \%$ of doses were associated with a potentially severe outcome. ${ }^{2}$ Whereas the study by Taxis et $a l^{2}$ investigated a cross section of intravenous drug administrations including a large number of doses given by injection, the study by Husch et $a l^{3}$ focused on intravenous drugs administered via infusion pumps. Their study of 286 patients receiving infusion therapy found that almost $70 \%$ of intravenous doses were associated with an error, including three (out of 389) errors potentially causing temporary harm or prolonging hospitalisation. These studies indicate the urgent need to identify measures to reduce medication errors.

Many strategies and technological advances have been discussed previously to reduce medication errors, including computerised physician order entry, participation of pharmacists on ward rounds, and bar coding of medication. The use of so-called "smart" infusion pumps is widely recommended to reduce intravenous medication administration errors. ${ }^{4}$ Smart pumps are infusion systems that allow entering drug infusion protocols into a library that can be used to specify pre-defined dose limits (with pumps alarming once these dose limits have been exceeded). Some measures, such as computerised physician order entry systems, ${ }^{5}$ have been shown to reduce medication errors in formal studies. However, little is known about the effects of smart pumps and thus the study by Husch and colleagues is timely. ${ }^{3}$ In contrast to common assumptions, they estimate that only one out of 389 errors related to the use of intravenous infusion devices may have been prevented by smart pumps. This was largely because the pumps currently available are insufficiently integrated into the system. For example, they are not linked to the electronic prescribing system or bar coded administration. The study clearly demonstrates that infusion devices need to be further developed to increase patient safety. The authors give a detailed outline of safety issues that need to be considered. Nonetheless, the potential of these infusion devices to reduce medication error must be ultimately tested in prospective studies.

Given that such ideal infusion devices have been developed, are we likely to see the reduction in medication errors when they are routinely used in practice? A recent report by the UK National Patient Safety Agency (NPSA) indicates that the situation may be far more complex than expected. ${ }^{6}$ The NPSA performed a pilot study in six hospitals and found that an unnecessary wide range of different types of infusion pumps were used within the hospitals. Furthermore, the software of devices of the same type had multiple configurations and therefore reacted differently under the same circumstances. In addition the report highlighted that there was insufficient and inadequate staff training in the use of devices. It remains unknown how generalisable these data are to healthcare systems in other countries; however, it is likely that the isolated introduction of yet another new infusion device will fail to improve patient safety unless there is a well-coordinated approach. This includes monitoring the practical use of the infusion devices to identify potential safety issues.

Providing intravenous drug therapy is a complex healthcare technology and different health professionals are involved in the process, including physicians, nurses, pharmacists, and medical engineers. Patients themselves and in some cases their carers also have an important role, in particular in patient controlled analgesic drug administration. Increasingly, pharmacists are seen (and want to be seen) as being responsible for medication safety issues in hospitals. For example, pharmacists perform regular prescription reviews in the UK, US, and Australian hospitals. Are they going to take the lead in this area? We have sufficient evidence about errors occurring with intravenous drug therapy and solutions are in sight. To achieve this goal, we need someone to take the responsibility for the safe and effective use of drug administration technologies. It's high time for action!

Qual Saf Health Care 2005; 14:76.

doi: 10.1136/qshc.2005.013706

Correspondence to: Dr K Taxis, Department of Social Pharmacy, Pharmacoepidemiology and Pharmacotherapy, Groningen University Institute for Drug Exploration (GUIDE), Ant.

Deusinglaan 1, 9713 AV Groningen, The Netherlands; k.taxis@rug.nl

\section{REFERENCES}

1 Dean B, Schachter M, Vincent C, et al. Prescribing errors in hospital inpatients: their incidence and clinical significance. Qual Saf Health Care 2002:11:340-4.

2 Taxis K, Barber N. Ethnographic study of incidence and severity of intravenous drug errors. BMJ 2003;326:684-7.

3 Husch M, Sullivan C, Rooney D, et al. Insights from the sharp end of intravenous medication errors: implications for infusion pump technology. Qual Saf Health Care 2005; 14:80-6.

4 Institute for Safe Medication Practices. "Smart" infusion pumps join CPOE and bar coding as important ways to prevent medication errors. 2005. http://www.ismp.org/msaarticles/ smartprint.htm (accessed 05.02.2005).

5 Bates DW, Leape LL, Cullen DJ, et al. Effect of computerized physician order entry and a team intervention on prevention of serious medication errors. JAMA 1998;280(15):1311-6.

6 National Patient Safety Agency. Safer practice notice - improving infusion device safety, 2004 www.npsa.nhs.uk (accessed 20.02.2005). 
Hospital performance

\section{Impact of reporting hospital performance}

\section{N Marshall, P S Romano}

\section{Is public disclosure a cost effective way to improve the quality of patient care?}

t doesn't seem long ago that many health professionals and managers were voicing passionate opposition to the public release of comparative information about provider performance. By and large, these voices have now gone quiet. In their place we hear more thoughtful discussions about how best to publish information in a way that engages the various audiences, maximises the benefits of disclosure, and minimises the potential for adverse consequences.

Why such a dramatic change? The argument in favour of publishing information about performance has been won in policy terms principally because of the contribution that disclosure can make to increasing the accountability of provider organisations. In more philosophical terms, many of the opponents of disclosure have been won over by arguments about the "right to know" of citizens in a democratic society.

Those who look for more instrumental reasons to justify the costly and complex task of publishing performance information have to search a little harder for supportive evidence. The original expectation in the United States, the home of so-called "report cards", was that informed and empowered consumers would use comparative information to select high quality providers or to demand better performance from lower quality providers. In fact, there is little empirical evidence that consumers use data in this way, and even less evidence that purchasers do so on behalf of consumers. ${ }^{1}$ In the UK it seems that most members of the public do not want to view health care as a market commodity and that they have a strong sense of responsibility for their local providers which leads them to distrust comparative information produced by external bodies. ${ }^{2}$ Furthermore, since people tend to make decisions about providers only when they need services, they are less likely to feel empowered to make rational decisions.

In contrast, provider organisations do seem to be sensitive to the publication of comparative performance data. ${ }^{3}$ For example, a report card on the structure and process of obstetric care was associated with the institution of car seat programs, follow up care, transfer agreements with tertiary care centres, and breastfeeding education at hospitals that were publicly reported not to offer these services. ${ }^{4}$ In a non-randomised controlled trial, a public report card on hospital complications was associated with markedly increased quality improvement activity (relative to either a private report card or none at all), especially among hospitals that received poor ratings. ${ }^{5}$ It is less clear whether the process changes stimulated by public report cards actually lead to improved outcomes. A now defunct public reporting program in Cleveland apparently shifted some deaths to post-discharge settings, leading to reduced 30 day mortality for two conditions, increased 30 day mortality for one condition, and no change for three conditions. ${ }^{6}$ New York's cardiac surgery reporting program stimulated a dramatic decrease in risk adjusted mortality, largely through focused interventions at high mortality hospitals, ${ }^{7}$ but northern New England achieved similar benefits through private reporting and sharing of best practices. $^{8}$

The big question-which we are only just starting to address-is the nature of these associations and whether there is a causal and unidirectional relationship between the publication of comparative information and improvements in the quality of care. Put simply, is public disclosure a cost effective way to improve the quality of patient care?

While there are potential mechanisms to explain how public disclosure might drive improvement-refocusing providers' attention on quality of care rather than financial performance, capitalising on the sensitivity of providers to their reputations and the innate competitiveness of clinicians and mangers-it has proved difficult to design evaluative studies. Most of the published research to date has used observational designs and most of this has been carried out in the United States.

In this issue of QSHC Ito and Sugawara ${ }^{9}$ contribute to the mounting body of observational evidence linking disclosure to performance using accreditation data from the Japanese health system. They report that small and medium sized hospitals that self-disclosed their accreditation reports received significantly higher scores on "efforts to meet community needs" and "medical/healthcare" than non-disclosing hospitals; no such difference was observed among large hospitals. There are methodological flaws with the study, including the unrepresentative sample of hospitals that volunteered for accreditation and the lack of standardisation of quality measures based on accreditation assessments. Nonetheless, their findings are consistent with those of other studies which have reported uniformly lower "effectiveness of care" among health plans that allow the National Committee for Quality Assurance to publicly disclose their Health Plan Employer Data and Information Set (HEDIS) scores than among health plans that do not, largely because poorly scoring plans withdraw from the public disclosure program. ${ }^{10}$ Similarly, hospitals that participate in California's voluntary cardiac surgery reporting scheme have lower unadjusted death rates than non-participating hospitals. ${ }^{11}$

It is difficult to judge from these studies whether public disclosure is something that only good hospitals are willing to do, or whether it actually leads to improved performance. This is a critical question because of its policy implications. Should public disclosure be mandatory because we expect it to stimulate quality improvement? Or should it remain voluntary, with confidential efforts to share best practices across hospitals and public efforts to applaud volunteers for their honesty and courage?

The challenge now facing the research community is to produce experimental evidence of the impact of disclosure on quality of care. This is a complicated task. There are problems with optimising the intervention because the content and presentation format of many report cards are deficient, and in determining the most appropriate outcomes. Examining patient movements between providers or insurance groups is relatively easy, but examining the impact on quality of care is more problematic. Even the strongest advocate of disclosure must accept that the effect size of publishing information is likely to be small and hence the sample size and costs of an experimental study are likely to be enormous.

Despite the increasing commitment to public disclosure of provider performance data, there is still much that we 
do not know about its cost effectiveness, impact, and mechanisms of action. The paper by Ito and Sugawara gives us one more piece in the jigsaw, but there are still significant challenges for the research community.

Qual Saf Health Care 2005; 14:77-78. doi: 10.1136/qshc.2005.013730

\section{Authors' affiliations}

M N Marshall, National Primary Care Research and Development Centre, University of Manchester, Manchester, UK P S Romano, Centre for Health Services Research in Primary Care, University of California Davis, School of Medicine, Sacramento, CA, USA

Correspondence to: Professor M N Marshall, National Primary Care Research and
Development Centre, University of Manchester, Manchester, UK; martin.marshall@man.ac.uk

\section{REFERENCES}

1 Schneider EC, Lieberman T. Publicly disclosed information about the quality of health care: response of the US public. Qual Health Care 2001;10:96-103.

2 Marshall M, Hiscock J, Sibbald B. A qualitative study of the attitudes of service users, general practitioners and clinical governance leads to comparative reports on quality in general practice. BMJ 2002;325:1278-82.

3 Marshall MN, Shekelle PG, Leatherman S, et al. The public release of performance data: what do we expect to gain, a review of the evidence. JAMA 2000;283:1866-74.

4 Longo DR, Land G, Schramm W, et al. Consumer reports in health care: do they make a difference in patient care? JAMA 1997;278:1579-84.

5 Hibbard JH, Stockard J, Tusler M. Does publicizing hospital performance stimulate quality improvement efforts? Health Aff 2003;22:84-94.

6 Baker DW, Einstadter D, Thomas CL, et al. Mortality trends during a program that publicly reported hospital performance. Med Care 2002;40:879-90.

7 Chassin M. Achieving and sustaining improved quality: lessons from New York State and cardiac surgery. Health Aff 2002;21:40-51.

8 Peterson ED, DeLong ER, Jollis JG, et al. The effects of New York's bypass surgery provider profiling on access to care and patient outcomes in the elderly. J Am Coll Cardiol 1998;32:993-9.

9 Ito $\mathrm{H}$, Sugawara $\mathrm{H}$. Relationship between accreditation scores and the public disclosure of accreditation reports: a cross sectional study. Qual Saf Health Care 2005; 14:87-92.

10 McCormick D, Himmelstein DU, Woolhandler S et al. Relationship between low quality-of-care scores and HMOs' subsequent public disclosure of quality-of-care scores. JAMA 2002;288: 1484-90.

11 Damberg CL, Danielson B, Parker JP, et al. The California report on coronary artery bypass graft surgery 1999 hospital data: summary report. San Francisco, CA: Pacific Business Group on Health and the California Office of Statewide Health

Planning and Development, 2003, 6. Available at http://www.oshpd.cahwnet.gov/HQAD/ Outcomes/Studies/cabg/1999report/

CCMRP\%20Summary/

SummaryPrefaceCCMRPstaff.pdf.

\section{Are the risks of hospital practice adequately recognised by incident reporting?}

\section{G Neale}

\section{The problem of patient safety is universal and more needs to be} done to engage the whole workforce at a national level

n a memorable quotation from the 1999 Hollister Lecture at Northwestern University, Illinois, Sir Cyril Chantler said "Medicine used to be simple, ineffective and relatively safe. Now it is complex, effective but potentially dangerous" ${ }^{1}$ For 50 years the dangers have been recognised, initially as diseases directly related to medications $^{2}$ and subsequently as hospital induced complications in which an early study showed that $20 \%$ of patients admitted to hospital were damaged by the care process. This was regarded as the price of medical progress. ${ }^{3}$ Neither the medical profession nor departments of health were prepared to address the issues. However, by the 1970s in the USA the insurance industry was crumbling under the weight of a growing number of claims of alleged medical negligence. To reveal the size of the problem the Californian Medical Association commissioned a group of doctors to develop a method of case record review. They showed that about
$1 \%$ of patients admitted to hospital suffered an iatrogenic event as a result of negligence. ${ }^{4}$ Ten years later the Commissioner of Health of New York State asked Harvard Medical School to re-examine the issues. The resulting study showed that defects in medical treatment caused disabling injuries in $3.7 \%$ of patients admitted to hospital. ${ }^{5}$ The insurance industry had temporarily stabilised and neither study made much impact.

It took the media to bring the problem to the surface-especially after Betsy Lehman, a Boston Globe reporter, died in 1995 from an overdose of cytotoxic drugs. ${ }^{6}$ At the end of 1999 the Institute of Medicine published the document "To Err is Human" in which it was asserted that $48000-98000$ Americans died in hospitals every year as a result of preventable errors, followed in 2000 by "Crossing the Quality Chasm" $^{\prime \prime} .{ }^{8}$ This led to a huge flurry of activity. Within 2 years 15 states had passed laws to make the reporting of adverse events mandatory; five states and the District of Columbia requested voluntary reporting systems.

Meanwhile, clinicians in Australia were quietly ahead of the game. In 1988, in Adelaide, Runciman had initiated incident monitoring and the following year the Australian Patient Safety Foundation (APSF) was established. ' Subsequently, a case record review study based on the Harvard model, ${ }^{10}$ but addressing quality of health care rather than negligent practice, showed that about one in six patients admitted to hospital were subject to adverse events of which half were deemed preventable. This prompted strong reactions from government, healthcare professionals, and the public at large. As a result, the Australian Incident Monitoring System (AIMS) was set up with APSF collecting and analysing the data generated. ${ }^{11}$ Many publications aimed at improving anaesthesia and intensive care followed.

In England and Wales action was triggered by several high profile cases of serious wrongdoing by individual doctors and by the Bristol scandal in paediatric cardiac surgery. ${ }^{12}$ The Chief Medical Officer was determined that clinicians should face the problem. ${ }^{13} 14$ In July 2001 the National Patient Safety Agency was established as a Special Health Authority. It aimed to develop a national reporting system for critical incidents. This has led to several national initiatives including measures to minimise risks of medications and of hospital acquired infection. ${ }^{15}$

But is incident reporting enough? Studies show that doctors remain unwilling to report. In 2003 Don Berwick, CE of the Institute for 
Healthcare Improvement, wrote "... so far I see no evidence that health care in the United States is becoming saferthe healthcare workforce remains blind to the enemy" ${ }^{\prime 16}$ This may be unfair to the VA Patient Safety Programme, ${ }^{17}$ but certainly the efforts to make hospital care safer are, at best, patchy.

How well do they do in Japan? In this issue of QSHC Nakajima and Coworkers ${ }^{18}$ describe a sophisticated system of voluntary anonymous computerised reporting in a 1000 bed hospital. It has an impressive management structure, facilitated feedback, educational seminars three times a year (with monitored attendance), ward rounds by peers, and ward checks by area clinical risk managers. 200 reports a month are received and the authors report examples of corrective action. Certainly the healthcare workforce in Osaka University Hospital must be well aware of safety problems. Yet, of the incidents reported, only $10 \%$ came from doctors. In their discussion Nakajima et al suggest that their system may miss episodes of "poor medical practice". This suggestion is supported by a report that slipped quietly into the medical literature. The research unit of the Royal College of Physicians of London set up a collaborative study in which experienced physicians examined the case records of 200 patients who died after being admitted to large general hospitals as emergencies. ${ }^{19}$ The reviewers agreed that, in 10\% of cases, erroneous management had contributed significantly to the fatal outcomes. Almost certainly, none of these cases were reported as incidents.

There is therefore a need to integrate other methods of recognising substandard hospital care with incident reporting. Wolff et $a l^{20}$ have shown how this may be achieved to good effect in a small community based hospital in Australia, and the recently described comparative methodology from Aquitaine provides additional interesting ideas. ${ }^{21}$ The problem of patient safety is universal and much more needs to be done to engage the whole workforce at a national level.

Qual Saf Health Care 2005; 14:78-79. doi: 10.1136/qshc.2004.013029

Correspondence to: Professor G Neale, Clinical Safety Research Unit, Academic Department of Surgery, St Mary's Hospital, London W2 INY, UK; g.neale@imperial.ac.uk

\section{REFERENCES}

1 Chantler C. The role and education of doctors in the delivery of healthcare. Lancet 1999;353:1178-81.

2 Barr DP. Hazards of modern diagnosis and therapy-the price we pay. JAMA 1956;159:1452-6.

3 Schimmel EM. The hazards of hospitalisation. Ann Intern Med 1964;60:100-10.

4 Mills DH. Medical insurance feasibility study: a technical summary. West J Med 1978;128:360-5.

5 Brennan TA, Leape LL, Laird NM, et al. Incidence of adverse events and negligence in hospitalized patients: results of the Harvard Medical Practice Study I. N Engl J Med 1991;324:370-6.
6 Anon. Betsy Lehman-influence on publicity of errors in hospital medical practice, http:// www.chiroweb.com/archives/13/12/03.html.

7 Institute of Medicine. To err is human: building a safer health system. Washington DC: National Academy Press, 1999.

8 Institute of Medicine. Crossing the quality chasm: a new health system for the 21 st century. Washington DC: National Academy Press, 2000

9 Australian Patient Safety Foundation. http:// www.apsf.net.au/about.html.

10 Wilson RM, Runciman WB, Gibbered RW, et al. The quality in Australian health care study. Med J Aust 1995; 163:458-71.

11 Runciman WB. Lessons from the Australian Patient Safety Foundation: setting up a national patient safety surveillance system - is this the right model? Qual Saf Health Care 2002;1 1:246-51.

12 Bristol Inquiry. http://www.bristolinquiry.org.uk.

13 Department of Health. An organisation with a memory: Report of an expert group on learning from adverse events in the NHS. London: Department of Health, 2000.

14 Department of Health. Building a safer NHS for patients. London: Department of Health, 2001.

15 National Patient Safety Agency. http:// www.npsa.nhs.uk.

16 Berwick DM. Errors today and errors tomorrow. N Engl J Med 2003;348:2570-2.

17 Stalhandske S, Bagian JP, Gosbee J. Department of Veterans Affairs Patient Safety Program. Am J Infect Control 2002:30:296-302.

18 Nakajima K, Kurata Y, Takeda H. A web-based incident reporting system and multidisciplinary collaborative projects for patient safety in a Japanese hospital. Qual Saf Health Care 2005; 14:123-9.

19 Seward E, Greig E, Preston S, et al. A confidential study of deaths after emergency admission: issues related to quality of care. Clin Med 2003:3:425-34.

20 Wolff AM, Bourke J, Campbell IA, et al. Detecting and reducing hospital adverse event outcomes of the Wimmera clinical risk management program. Med J Aust 2001;174:621-5.

21 Michel P, Quenon JL, de Sarasqueta AM, et al. Comparison of three methods for estimating rates of adverse events and rates of preventable adverse events in acute care hospitals. $B M$ 2004;329: 199-203. 